\title{
Rigas Pheraios. Un nouveau bilan de la recherche. Jannina, 28 - 31 mai 1998.
}

\section{Catherine Koumarianou}

\section{(2) OpenEdition \\ Journals}

Édition électronique

URL : https://journals.openedition.org/ahrf/2268

DOI : 10.4000/ahrf.2268

ISSN : 1952-403X

\section{Éditeur :}

Armand Colin, Société des études robespierristes

\section{Édition imprimée}

Date de publication : 1 mars 2000

Pagination : 136-138

ISSN : 0003-4436

\section{Référence électronique}

Catherine Koumarianou, « Rigas Pheraios. Un nouveau bilan de la recherche. Jannina, 28 - 31 mai

1998. », Annales historiques de la Révolution française [En ligne], 319 | janvier-mars 2000, mis en ligne le 11 mai 2006, consulté le 24 avril 2022. URL : http://journals.openedition.org/ahrf/2268 ; DOI : https:// doi.org/10.4000/ahrf.2268

Ce document a été généré automatiquement le 24 avril 2022.

Tous droits réservés 


\title{
Rigas Pheraios. Un nouveau bilan de la recherche. Jannina, 28 - 31 mai 1998.
}

\author{
Catherine Koumarianou
}

1 Le congrès organisé par l'université de Jannina avait comme objectif principal, en dehors de la présentation d'études concernant la vie et l'œuvre de Rigas, tout élément nouveau dû aux recherches effectuées dans les derniers temps. C'est justement par le sous-titre du sujet du congrès "Un nouveau bilan de la recherche", que les organisateurs, membres de la faculté de Philosophie de ladite université, ont voulu souligner l'importance des éléments nouveaux qu'ils attendaient récolter au cours des travaux du congrès.

2 Personnalité parmi les plus appréciées de l'Aufklärung grecque, Rigas Velestinlis, intellectuel, homme politique, révolutionnaire, avait attiré, depuis longtemps déjà l'intérêt des chercheurs, spécialistes de l'histoire de la Grèce moderne. Ainsi, on a abordé le thème concernant les études que Rigas a faites auprès de D. Katardjis et de son cercle de Bucarest, dans la décennie de 1780, en soulignant qu'il a tiré grand profit de la fréquentation du savant juriste et linguiste que fut D. Katardjis (Catherine Koumarianou). Les livres qu'il a publiés dans la décennie 1790, tant littéraires que scientifiques, rédigés en langue démotique, ont été examinés par les chercheurs qui ont parlé du projet conçu par Rigas de procurer, au public grec, des textes écrits en un langage familier et, par conséquent, faciles à comprendre, donc utiles à la diffusion des connaissances. Par la suite, de nouvelles données ont été présentées concernant les livres que Rigas a fait paraitre sur les presses de Vienne, destinés aux écoles et à l'enseignement, la langue qu'il a adoptée pour aider les écoliers dans l'apprentissage des matières enseignées et l'utilisation de l'expérience, physique et chimique (Y. Karas, G.Vlachakis, E. Nikolaïdis).

3 Les préoccupations de Rigas dans le domaine politique, telles qu'elles apparaissent dans ses écrits et ses activités, ont été évoquées par d'autres participants qui ont considéré sa réflexion politique, formée par la fréquentation des milieux phanariotes, couche 
dominante à l'époque dans les Principautés danubiennes, ainsi que par son service auprès de princes phanariotes, régnant dans ces contrées, service qui lui a donné l'occasion de connaître et étudier la situation politique de l'Europe centrale, des pays balkaniques, de l'Empire ottoman, en cette fin de siècle. Ses écrits politiques, d'autre part, ont donné l'occasion à des congressistes, juristes et sociologues, de commenter certains articles de la Constitution de Rigas, rédigée d'après la Constitution française de 1793, afin de faire le rapprochement de ses réflexions et théories politiques avec les opinions et les idées exprimées par les écrits de la France révolutionnaire. Il a été souligné que ses écrits politiques, notamment sa Constitution, étaient un manifeste idéologique que Rigas avait rédigé dans le but d'encourager, sinon d'assurer, la solidarité des peuples balkaniques face au sultan; dans le but, aussi, d'encourager les actions de ses compatriotes contre, non seulement le despote ottoman, mais aussi la tyrannie. Des interventions intéressantes ont été faites par les mêmes participants, sur les termes introduits par Rigas dans ses textes politiques, tels " nation », " national», " peuple », « liberté du peuple », « liberté de la nation », « liberté politique », et autres, avec des remarques pertinentes sur la signification de ces termes à l'époque et sur leur réception (A. Manessis, C. Tsoukalas).

4 Les retentissements de ses activités, sentis tout au long du xixe siècle, sur le plan politique et social dans l'État grec libre, à savoir la fondation d'associations démocratiques au milieu du siècle, quelques-unes portant même le nom de Rigas, l'évocation de son nom par les instigateurs du mouvement de la "grande idée », ont permis la discussion sur l'influence exercée par la personnalité de Rigas sur les affaires nationales, sociales et politiques de la Grèce du xixe siècle (P. Noutsos, I. Papakostas). La condamnation du mouvement révolutionnaire de Rigas par le Patriarcat de Constantinople, les textes écrits par des cercles ecclésiastiques pour s'opposer à ses activités «subversives", la problématique fondée sur l'attitude ouvertement négative de l'Église face aux activités de Rigas, ont donné lieu à des remarques fort intéressantes (Ph. Iliou).

5 L'œuvre littéraire, la poésie de Rigas, la tradition manuscrite de sa production, sa personnalité même telle qu'elle apparaît dans la littérature grecque du xixe siècle, ont été traitées par des participants qui ont présenté à cet effet, du matériel nouveau et inédit (E. Kapsomenos, M. Papathomopoulos).

6 D'autre part, on a évoqué les liens secrets que Rigas a essayé d'établir avec la diplomatie et la politique françaises, intéressées à l'époque par la région de la Méditerranée orientale ; en examinant l'éventualité de ce rapprochement en relation avec la politique supposée "francophile» d'Ali Pasha de Jannina, aussi bien en considération avec une intervention favorable des deux parties pour la cause des Grecs. En même temps, ont été évoqués ses préparatifs pour organiser le mouvement révolutionnaire dans les régions de l'Empire et des îles Ioniennes, mieux indiquées, selon lui, pour un soulèvement contre l'oppresseur ottoman (V. Panayotopoulos). 